\title{
EXAME DE COLPOCITOLOGIA ONCÓTICA: REVISÃO INTEGRATIVA
}

PAP SMEAR EXAM: INTEGRATIVE REVIEW

EXAMEN DE COLPOCITOLOGIA ONCÓTICA: REVISIÓN INTEGRADORA

\author{
Luana Tainá Lima Amorim ${ }^{1}$; Nicole Jucá Monteiro ${ }^{2}$; Laura Maria Vidal Nogueira ${ }^{3}$; Ivaneide \\ Leal Ataíde Rodrigues ${ }^{4}$; Suzana Rosa André ${ }^{5}$
}

\section{RESUMO}

Este artigo tem como tema, o exame de colpocitologia oncótica realizado nas Unidades de Saúde. Objetivo: O objetivo do estudo é evidenciar o que as publicações científicas nacionais e internacionais revelam sobre a qualidade dos serviços que realizam o exame Papanicolau. Método: Como metodologia, utilizou-se a revisão integrativa da literatura, realizando busca de dados nas bases US National Library of Medicine e da Literatura Latino Americana e do Caribe em Ciências da Saúde. Resultados: Totalizou-se 31 estudos para análise, dos quais 64,5\% (20 artigos) foram publicados em periódicos nacionais e 34,4\% (11) publicados em periódicos estrangeiros. Os estudos foram agrupados em três categorias conforme conteúdo a saber: conhecimento sobre o exame de colpocitologia oncótica; acesso ao serviço de saúde na Atenção Primária e análise laboratorial. Conclusão: Este estudo identificou a importância do teste de Papanicolau para a população feminina, assim como sua relação e importância nas práticas dos profissionais da enfermagem.

Descritores: Teste de Papanicolau; Controle de Qualidade; Colo de útero; Atenção Primária à Saúde.

\begin{abstract}
This article focuses on the examination of Pap smear done in the health units. Objective: The aim of the study is to show que the national and international scientific publications reveal about the quality of services que perform pap smears. Method: The methodology used the integrative literature review, conducting a search in the data bases US National Library of Medicine and the Latin American and Caribbean Health Sciences. Results: 31 totaled up studies for analysis, of which $64.5 \%$ (20 articles) were published in national journals and $34.4 \%$ (11) published in foreign journals. The studies were grouped into three categories According to content, namely: knowledge about the examination of oncotic colpocitology; Access to health service in Primary Care and laboratory analysis. Conclusion: This study identified the importance of the Pap test for the female population.
\end{abstract}

Keywords: Pap Test; Quality control; Cervix uteri; Primary Health Care.

\footnotetext{
${ }^{1}$ Universidade do Estado do Pará, Graduanda na Escola de Enfermagem Magalhães Barata, Belém - PA, Brasil. Email:luamorim29@hotmail.com

${ }^{2}$ Universidade do Estado do Pará, Graduanda na Escola de Enfermagem Magalhães Barata, Belém - PA, Brasil. Email:nicolejuca@gmail.com

${ }^{3}$ Universidade do Estado do Pará, Doutora em Enfermagem - EEAN/UFRJ, Escola de Enfermagem Magalhães Barata, Belém - PA, Brasil. Email: lauramavidal@gmail.com

${ }^{4}$ Universidade do Estado do Pará, Doutora em Enfermagem - EEAN/UFRJ, Escola de Enfermagem Magalhães Barata, Belém - PA, Brasil. Email: ilar@globo.com

5 Universidade do Estado do Pará, Mestranda do Programa de Enfermagem UEPA/UFAM, Escola de Enfermagem Magalhães Barata, Belém - PA, Brasil. Email: suzanarandre@ gmail.com
} 


\section{RESUMEN}

Este artículo tiene como tema, el examen de colpocitologia oncótica realizado en las Unidades de Salud. Objetivo: El objetivo del estudio es evidenciar lo que las publicaciones científicas nacionales e internacionales revelan sobre la calidad de los servicios que realizan el examen Papanicolau. Método: Como metodología, se utilizó la revisión integrativa de la literatura, realizando una búsqueda de datos en las bases US National Library of Medicine y de la Literatura Latinoamericana y del Caribe en Ciencias de la Salud. Resultados: Se totalizaron 31 estudios para análisis, de los cuales 64,5 (20 artículos) fueron publicados en periódicos nacionales y el 34,4\% (11) publicados en periódicos extranjeros. Los estudios se agruparon en tres categorías según el contenido, a saber: conocimiento sobre el examen de colpocitología oncótica; acceso al servicio de salud en la Atención Primaria y análisis de laboratorio. Conclusión: Este estudio identificó la importancia del test de Papanicolau para la población femenina, así como su relación e importancia en las prácticas de los profesionales de la enfermería.

Descriptores: Prueba de Papanicolau; Control de calidad; Cuello del Útero; Atención Primaria de Salud.

\section{INTRODUÇÃO}

O câncer de colo uterino é o segundo tipo mais comum entre mulheres no mundo e representa um grave problema de saúde pública no Brasil. De acordo com a estimativa do Instituto Nacional do Câncer (INCA) para 2016/2017, serão registrados no país cerca de 596 mil novos casos de câncer, dos quais 295.200 são esperados na população masculina, e $300.800 \mathrm{em}$ mulheres, sendo que o câncer de próstata será o de maior incidência entre os homens e o de mama o de maior ocorrência entre as mulheres. Esses dados corroboram o documento da Organização Mundial de Saúde (OMS) denominado World Cancer report 2014 da International Agency for Researchon Cancer (Iarc), que descreve sobre o quanto o câncer é um problema de saúde pública e merece atenção especial, sobretudo nas ações de prevenção e controle dos fatores de risco presentes na população. ${ }^{1}$

O câncer de colo de útero, se diagnosticado precocemente, apresenta grande probabilidade de cura, além de contar com muitas formas de prevenção disponíveis e acessíveis no Sistema Único de Saúde (SUS). ${ }^{1}$ Mesmo assim, é responsável por elevado número de mortes em mulheres - principalmente em regiões menos desenvolvidas ${ }^{1}$ sendo o rastreamento por meio do exame de colpocitologia oncótica para detecção precoce do câncer de colo de útero, de grande importância para a manutenção da saúde da mulher, devendo a sua coleta ser baseada em protocolos e ser realizada por profissionais capacitados e habilitados para a mesma. Deve ainda contemplar os padrões de qualidade que são estabelecidos 
e necessários para uma coleta eficiente e adequada. $^{2}$

É importante salientar que a Resolução do COFEN No 381/2011, refere que a coleta de material para a colpocitologia oncótica pelo método Papanicolau é privativo do enfermeiro, levando-se em consideração as disposições legais da profissão, devendo o mesmo estar apto para exercer a função. ${ }^{3}$

Este estudo tem como objetivo identificar o que as publicações científicas nacionais e internacionais revelam sobre a qualidade dos serviços que realizam o exame Papanicolau utilizando como ferramenta o instrumento Service Quality (servqual). $^{4}$

\section{MÉTODO}

O método do estudo constituiu-se de uma revisão integrativa da literatura, que permite a construção do processo de sistematização e análise dos resultados, visando a compreensão de um tema específico, a partir de outros estudos independentes. ${ }^{5}$

Inicialmente, foram definidos os descritores da pesquisa de acordo com os Descritores em Ciências da Saúde (Decs): "teste de Papanicolau"; "Enfermagem"; "Controle de Qualidade" e "Colo de Útero". Além disso, foi utilizada uma palavra chave denominada: "Servqual em Saúde". A partir daí, foram feitas as associações para buscas nas bases de dados: "Teste de Papanicolau AND Enfermagem"; "Teste de Papanicolau AND Controle de Qualidade"; "Colo de Útero $A N D$ Enfermagem"; "Colo de útero $A N D$ Controle de Qualidade" e "Servqual em Saúde".

Após, foram definidos os critérios de inclusão e exclusão. Para inclusão: artigos completos, teses e dissertações disponíveis em acesso aberto nas bases de dados, nos idiomas português, inglês e espanhol e correspondessem ao período 2007 a 2017. Para exclusão: as publicações duplicadas.

Com isso, foram feitas as buscas nas bases de dados da Literatura LatinoAmericana e do Caribe em Ciências da Saúde (LILACS) e US National Library of Medicine (PUBMED) utilizando os descritores com o operador boleano “AND” para compor as associações. Foram encontradas 723 publicações disponíveis no LILACS e 364 publicações no PUBMED. Foi realizada a filtragem ressaltando que muitas publicações não estavam disponíveis na íntegra ou mesmo com acesso aberto. Portanto, restaram 21 artigos da LILACS e 5 do PUBMED, totalizando 26 artigos.

Para organização e tabulação dos dados, utilizou-se uma planilha no programa excel contendo: título, autores, periódico, ano de publicação, objetivos do estudo, país do estudo, população 
estudada, método utilizado, resultados, discussões e conclusão, os quais são referenciados no presente texto.

\section{RESULTADOS}

Pôde-se constatar que 73,07\% (19 artigos) foram publicados em periódicos brasileiros e 26,92\% (7 artigos) em periódicos estrangeiros. Os países de origem do estudo estavam assim distribuídos: Brasil 84,61\% (22), Estados Unidos (EUA) 3,84\% (1), Turquia 3,84\% (1), Inglaterra 3,84\% (1) e Irã 3,84 \% (1).

Os estudos selecionados foram classificados quanto ao seu paradigma metodológico, conforme explicitado nos periódicos. Quanto à abordagem: 57,69\% (15) estudos qualitativos, 38,46\% (10) estudos quantitativos e $3,84 \%$ (1) quantitativo/qualitativo. Quanto à natureza das publicações: 84,61\% (22) estudos de natureza aplicada e 15,38\% (4) de natureza básica. Quanto ao objetivo: 61,53\% (16) eram estudos descritivos, 34,61\% (9) estudos exploratórios e $3,84 \% \quad$ (1) explicativos.
Em relação ao ano de publicação, distribuíram-se da seguinte forma: 7,69\% (2 artigos) em 2008, 3,84\% (1 artigo) em 2009, 11,53\% (3 artigos) em 2011, 11,53\% (3 artigos) em 2012, 19,23\% (5 artigos) em 2013, 19,23\% (5 artigos) em 2014, 19,23\% (5 artigos) em 2015 e 7,69\% (2 artigos) em 2016.

Quanto ao contexto em que os estudos foram desenvolvidos, 34,61\% (9 artigos) foram realizados diretamente junto às mulheres, utilizando a entrevista para obtenção de dados relacionados ao exame de colpocitologia oncótica. 7,69\% (2 artigos) foram realizados com laboratórios que processavam os exames e faziam leitura das lâminas do preventivo do câncer de colo de útero. 7,69\% (2 artigos) foram realizados para avaliar o processo de trabalho em relação ao exame nas Unidades Básicas de Saúde, 30,43\% (7 artigos) avaliaram esfregaços cervicais e $23,07 \%$ (6 artigos) foram realizados com enfermeiros, acadêmicos de enfermagem e de medicina sobre as práticas vivenciadas no serviço.

Quadro 1: Disposição dos artigos selecionados, de acordo com título, autores, ano de publicação e objetivo.

\begin{tabular}{|c|c|c|c|}
\hline Título & Autores & Ano & Objetivos \\
\hline $\begin{array}{l}\text { Access to Papanicolaou Test by the Unified Health } \\
\text { System users }\end{array}$ & $\begin{array}{l}\text { CARVALHO, V. F; } \\
\text { KERBER, N. P. C; } \\
\text { WACHHOLZV. A; } \\
\text { POHLMANN, F. } \\
\text { C; MARQUES, } \\
\text { L.A; FRANCIONI, }\end{array}$ & 2016 & $\begin{array}{l}\text { Compreender } \\
\text { como se dá o } \\
\text { acesso } \\
\text { usuárias das } \\
\text { serviço público } \\
\text { de saúde ao }\end{array}$ \\
\hline
\end{tabular}




\begin{tabular}{|c|c|c|c|}
\hline & F.F. & & $\begin{array}{l}\text { exame } \\
\text { Papanicolau. }\end{array}$ \\
\hline $\begin{array}{l}\text { CA de colo uterino: conhecimento e comportamento } \\
\text { de mulheres para prevenção }\end{array}$ & $\begin{array}{l}\text { SANTOS, A. M. R; } \\
\text { HOLANDA, J. B. } \\
\text { L; SILVA, J. M. O; } \\
\text { SANTOS, A. A. P; } \\
\text { SILVA, E. M. }\end{array}$ & 2015 & $\begin{array}{l}\text { Analisar } \\
\text { conhecimento } \\
\text { das mulheres } \\
\text { em relação à } \\
\text { prevenção do } \\
\text { câncer de colo } \\
\text { de útero e os } \\
\text { fatores } \\
\text { dificultadores } \\
\text { acerca da } \\
\text { realização do } \\
\text { exame } \\
\text { preventivo. }\end{array}$ \\
\hline $\begin{array}{l}\text { Conhecimento cotidiano de mulheres sobre a } \\
\text { prevenção do câncer de colo do útero }\end{array}$ & $\begin{array}{l}\text { NASCIMENTO, L. } \\
\text { C; NERY, I. S; } \\
\text { SILVA, A O. }\end{array}$ & 2012 & $\begin{array}{l}\text { Apreender as } \\
\text { representações } \\
\text { sociais } \\
\text { elaboradas por } \\
\text { mulheres, acerca } \\
\text { da prevenção do } \\
\text { câncer de colo } \\
\text { do útero, bem } \\
\text { como analisar } \\
\text { como essas } \\
\text { representações } \\
\text { influem na } \\
\text { realização do } \\
\text { exame. }\end{array}$ \\
\hline $\begin{array}{l}\text { Estrutura e processo de trabalho na prevenção do } \\
\text { câncer de colo de útero na Atenção Básica à Saúde } \\
\text { no Brasil: Programa de Melhoria do Acesso e da } \\
\text { Qualidade - PMAQ }\end{array}$ & 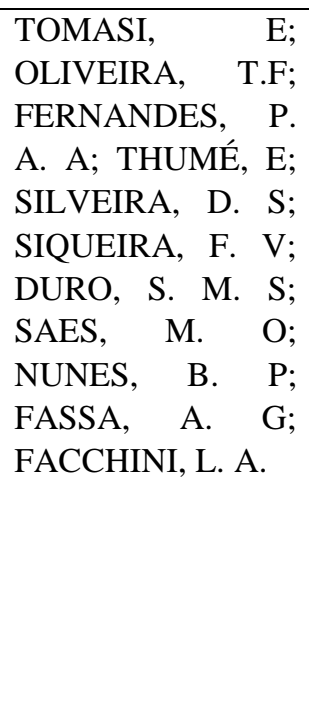 & 2015 & 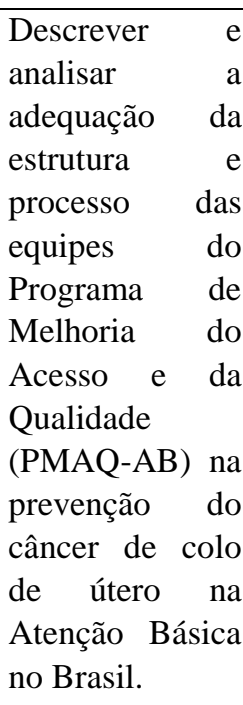 \\
\hline $\begin{array}{l}\text { Significados do fazer profissional na estratégia de } \\
\text { saúde da família: atenção básica enquanto cenário de } \\
\text { atuação }\end{array}$ & $\begin{array}{l}\text { MACHADO, L. M; } \\
\text { COLOMÉ, } \\
\text { SILVA, } \quad \text { R.S; } \\
\text { SANGOI, T. } \\
\text { FREITAS, N. Q. }\end{array}$ & 2016 & $\begin{array}{l}\text { Conhecer os } \\
\text { significados do } \\
\text { fazer } \\
\text { profissional } \\
\text { atribuídos pelos } \\
\text { profissionais de } \\
\text { saúde que atuam } \\
\text { em uma }\end{array}$ \\
\hline
\end{tabular}




\begin{tabular}{|c|c|c|c|}
\hline & & & $\begin{array}{l}\text { Estratégia Saúde } \\
\text { da Família. }\end{array}$ \\
\hline $\begin{array}{l}\text { Educação popular como instrumento participativo } \\
\text { para a prevenção do câncer ginecológico: percepção } \\
\text { de mulheres }\end{array}$ & $\begin{array}{lr}\text { SOUZA, } & \text { K; } \\
\text { PAIXÃO, G. } & \text { P; } \\
\text { ALMEIDA, } & \text { E; } \\
\text { SOUSA, A; LIRIO, } \\
\text { J; CAMPOS, L. }\end{array}$ & 2015 & $\begin{array}{l}\text { Avaliar } \\
\text { percepção de } \\
\text { mulheres sobre } \\
\text { o câncer do colo } \\
\text { do útero, através } \\
\text { da prática de } \\
\text { educação } \\
\text { popular. }\end{array}$ \\
\hline $\begin{array}{l}\text { Alterações Citopatológicas, Doenças Sexualmente } \\
\text { Transmissíveis e Periodicidade dos Exames de } \\
\text { Rastreamento em Unidade Básica de Saúde }\end{array}$ & $\begin{array}{lr}\text { LAGANÁ, } & \text { M. T.C; } \\
\text { SILVA, } & \text { M.M.P; } \\
\text { LIMA, } & \text { L.F, } \\
\text { FRANÇA, T.L.B. }\end{array}$ & 2013 & $\begin{array}{l}\text { Verificar a } \\
\text { periodicidade de } \\
\text { realização de } \\
\text { exames } \\
\text { citopatológicos } \\
\text { e identificar a } \\
\text { frequência de } \\
\text { alterações } \\
\text { citopatológicas } \\
\text { nos registros em } \\
\text { Unidade Básica } \\
\text { de Saúde. }\end{array}$ \\
\hline $\begin{array}{l}\text { Formação do enfermeiro para a prevenção do câncer } \\
\text { de colo uterino }\end{array}$ & $\begin{array}{l}\text { VIANA, M.R.P; } \\
\text { MOURA, M.E.B; } \\
\text { NUNES, B.M.V.T; } \\
\text { MONTEIRO, } \\
\text { C.F.S; LAGO, E.C. }\end{array}$ & 2013 & $\begin{array}{lr}\text { Analisar } & \text { a } \\
\text { formação do } & \text { do } \\
\text { enfermeiro para } \\
\text { a prevenção do } \\
\text { câncer de } & \text { colo } \\
\text { uterino no } & \text { no } \\
\text { contexto da } \\
\text { Estratégia Saúde } \\
\text { da Família. }\end{array}$ \\
\hline $\begin{array}{l}\text { Atenção básica em saúde: prevenção do câncer de } \\
\text { colo do útero na consulta de enfermagem }\end{array}$ & $\begin{array}{lr}\text { SILVA, } & \text { M.M; } \\
\text { GITSOS, } & \text { J; } \\
\text { SANTOS, N.L.P. }\end{array}$ & 2013 & $\begin{array}{l}\text { Analisar os } \\
\text { eixos teórico- } \\
\text { conceituais } \\
\text { estruturantes da } \\
\text { consulta de } \\
\text { enfermagem } \\
\text { ginecológica na } \\
\text { atenção básica } \\
\text { (AB) e discutir } \\
\text { as principais } \\
\text { condutas } \\
\text { implementadas } \\
\text { para prevenção } \\
\text { do câncer do } \\
\text { colo do útero } \\
\text { (CCU). }\end{array}$ \\
\hline $\begin{array}{l}\text { Educação em Saúde para a Prevenção do Câncer } \\
\text { Cérvico-uterino }\end{array}$ & $\begin{array}{l}\text { RODRIGUES, B.C; } \\
\text { CARNEIRO, } \\
\text { A.C.M.O; SILVA, } \\
\text { T.L; SOLÁ, A.C.N; } \\
\text { MANZI, } \quad \text { N.M; }\end{array}$ & 2010 & $\begin{array}{l}\text { Realizar } \\
\text { atividades de } \\
\text { educação em } \\
\text { saúde dentro do } \\
\text { tema prevenção }\end{array}$ \\
\hline
\end{tabular}




\begin{tabular}{|c|c|c|c|}
\hline & $\begin{array}{l}\text { SCHECHTMAN, } \\
\text { N.P; } \\
\text { MAGALHÃES, } \\
\text { H.L.G.O; DYTZ, } \\
\text { J.L.G. }\end{array}$ & & $\begin{array}{l}\text { de câncer } \\
\text { cérvico-uterino. }\end{array}$ \\
\hline $\begin{array}{l}\text { Prevenção do câncer de colo uterino: adesão de } \\
\text { enfermeiros e usuárias da atenção primária }\end{array}$ & $\begin{array}{l}\text { MENDONÇA, } \\
\text { F.A.C; SAMPAIO, } \\
\text { L.R.L; JORGE, } \\
\text { R.J.B; SILVA, } \\
\text { R.M; LINARD, } \\
\text { A.G; VIEIRA, } \\
\text { N.F.C. }\end{array}$ & 2011 & $\begin{array}{l}\text { Analisar a } \\
\text { compreensão de } \\
\text { enfermeiros e } \\
\text { usuárias da } \\
\text { atenção primária } \\
\text { sobre a adesão } \\
\text { da prevenção do } \\
\text { câncer de colo } \\
\text { uterino. }\end{array}$ \\
\hline $\begin{array}{l}\text { Câncer de colo uterino: realização do exame } \\
\text { colpocitológico e mecanismos que ampliam sua } \\
\text { adesão }\end{array}$ & $\begin{array}{ll}\text { FELICIANO, } & \text { C; } \\
\text { CHRISTEN, } & \text { K; } \\
\text { VELHO, M.B. } & \end{array}$ & 2010 & $\begin{array}{lr}\text { Identificar } & \text { o } \\
\text { perfil e } & \text { os } \\
\text { mecanismos } & \text { que } \\
\text { ampliam } & \text { a } \\
\text { adesão } & \text { das } \\
\text { mulheres } & \text { na } \\
\text { realização } & \text { do } \\
\text { exame } & \\
\text { colpocitológico } \\
\text { no Sistema } \\
\text { Único de Saúde. }\end{array}$ \\
\hline $\begin{array}{l}\text { Fatores associados a não realização periódica do } \\
\text { exame Papanicolau }\end{array}$ & $\begin{array}{l}\text { JORGE, R.J.B; } \\
\text { SAMPAIO, L.R.L; } \\
\text { DIÓGENES, } \\
\text { M.A.R; } \\
\text { MENDONÇA, } \\
\text { F.A.C; SAMPAIO, } \\
\text { L.L. }\end{array}$ & 2011 & $\begin{array}{ll}\text { Conhecer } & \text { os } \\
\text { fatores } & \\
\text { associados a não } \\
\text { realização } \\
\text { periódica do } \\
\text { exame } \\
\text { Papanicolau. }\end{array}$ \\
\hline $\begin{array}{l}\text { Indicadores de qualidade dos exames citopatológicos } \\
\text { da rede pública em Minas Gerais, Brasil }\end{array}$ & $\begin{array}{lr}\text { TOBIAS, } & \text { A.H.G; } \\
\text { AMARAL, } & \text { R.G; } \\
\text { DINIZ, } & \text { E.M; } \\
\text { CARNEIRO, C.M. }\end{array}$ & 2016 & $\begin{array}{l}\text { Avaliar } 0 \\
\text { desempenho dos } \\
\text { laboratórios de } \\
\text { citopatologia } \\
\text { prestadores de } \\
\text { serviço para o } \\
\text { Sistema Único } \\
\text { de Saúde (SUS). }\end{array}$ \\
\hline $\begin{array}{l}\text { Qualidade em citopatologia: análise de indicadores } \\
\text { de monitoramento interno de qualidade do Instituto } \\
\text { Nacional de Câncer }\end{array}$ & 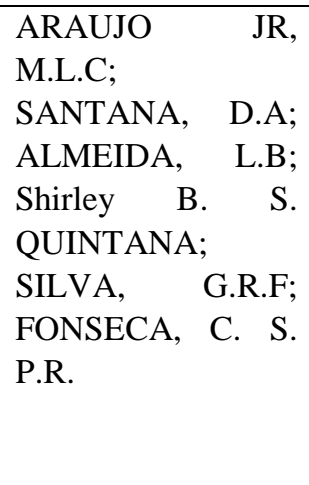 & 2015 & $\begin{array}{lr}\text { Análise } & \text { dos } \\
\text { indicadores } & \text { da } \\
\text { fase } & \text { pós- } \\
\text { analítica } & \text { do } \\
\text { programa } & \text { de } \\
\text { monitoramento } \\
\text { interno } \\
\text { qualidade } & \\
\text { (IQM) } & \\
\text { laboratórios de } & \text { de } \\
\text { citopatologia }\end{array}$ \\
\hline
\end{tabular}




\begin{tabular}{|c|c|c|c|}
\hline $\begin{array}{l}\text { Avaliação dos Indicadores da Qualidade dos Exames } \\
\text { Citopatológicos do Colo do Útero de Laboratórios } \\
\text { Privados do Estado de Goiás credenciados pelo } \\
\text { Sistema Único de Saúde }\end{array}$ & $\begin{array}{l}\text { ÁZARA, } \quad \text { C.Z.S; } \\
\text { ARAÚJO, E.S; } \\
\text { MAGALHÃES, } \\
\text { J.C; AMARAL, } \\
\text { R.G. }\end{array}$ & 2014 & $\begin{array}{l}\text { Avaliar cinco } \\
\text { indicadores de } \\
\text { monitoramento } \\
\text { interno da } \\
\text { qualidade dos } \\
\text { laboratórios } \\
\text { privados, } \\
\text { credenciados } \\
\text { pelo Sistema } \\
\text { Único de Saúde. }\end{array}$ \\
\hline $\begin{array}{l}\text { Internal quality control indicators of cervical } \\
\text { cytopathology exams performed in laboratories } \\
\text { monitored by the External Quality Control } \\
\text { Laboratory }\end{array}$ & $\begin{array}{l}\text { ÁZARA, C.Z.S; } \\
\text { MANRIQUE, } \\
\text { E.J.C; TAVARES, } \\
\text { S.B.N; SOUZA, } \\
\text { N.L.A; AMARAL, } \\
\text { R.G. }\end{array}$ & 2014 & 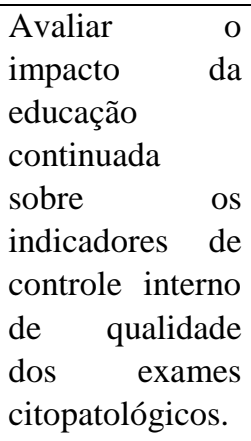 \\
\hline $\begin{array}{l}\text { Avaliação dos indicadores de qualidade de } \\
\text { laboratórios de citopatologia cervical }\end{array}$ & $\begin{array}{lr}\text { PLEWKA, } & \mathrm{J} ; \\
\text { TURKIEWICZ, M; } & \text { DUARTE, } \\
\text { CHAVES, } & \text { M.A.F; } \\
\text { CESTARI, } & \text { C; } \\
\text { TARTARI, D.C. }\end{array}$ & 2014 & $\begin{array}{l}\text { Avaliar o } \\
\text { desempenho dos } \\
13 \text { laboratórios } \\
\text { que realizaram o } \\
\text { exame } \\
\text { citopatológico } \\
\text { para o SUS no } \\
\text { Paraná. }\end{array}$ \\
\hline $\begin{array}{l}\text { O controle do câncer do colo do útero: desafios para } \\
\text { implementação de ações programáticas no } \\
\text { Amazonas, Brasil }\end{array}$ & $\begin{array}{l}\text { CORRÊA, D.A.D; } \\
\text { VILLELA, W.V. }\end{array}$ & 2008 & \begin{tabular}{l}
\multicolumn{2}{l}{ Demonstrar } \\
alguns desafios \\
para a \\
implementação \\
de ações \\
programáticas \\
visando ao \\
controle do \\
câncer do colo \\
do útero.
\end{tabular} \\
\hline $\begin{array}{l}\text { Câncer cérvico-uterino como condição marcadora: } \\
\text { uma proposta de avaliação da atenção básica }\end{array}$ & $\begin{array}{l}\text { BOTTARI, C.M.S; } \\
\text { VASCONCELLOS, } \\
\text { M.M; } \\
\text { MENDONÇA, } \\
\text { M.H.M. }\end{array}$ & 2008 & 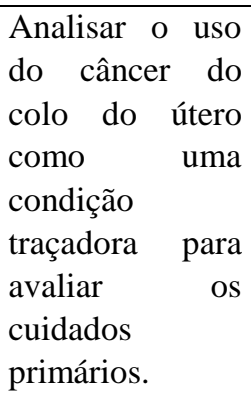 \\
\hline $\begin{array}{l}\text { The use of the quality model of Parasuraman, } \\
\text { Zeithaml and Berry in health services. }\end{array}$ & $\begin{array}{l}\text { PENA, M.M; } \\
\text { SILVA, E.M.S; } \\
\text { TRONCHIN, } \\
\text { D.M.R; } \\
\text { MELLEIRO, M.M. }\end{array}$ & 2013 & $\begin{array}{lr}\text { Refletir acerca } \\
\text { do modelo } \\
\text { avaliação } & \text { da } \\
\text { qualidade } & \text { em } \\
\text { serviços } & \text { de }\end{array}$ \\
\hline
\end{tabular}




\begin{tabular}{|c|c|c|c|}
\hline & & & 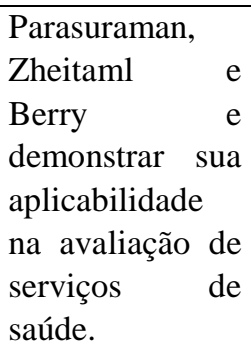 \\
\hline $\begin{array}{l}\text { Women's awareness of the human papilloma virus } \\
\text { and related health problems. }\end{array}$ & $\begin{array}{lr}\text { AKYUZ, } & \text { A; } \\
\text { YILMAZ, } & \text { C; } \\
\text { YENEN, } & \text { M.C; } \\
\text { YAVAN, } & \text { T; } \\
\text { KILIÇ, A. } & \end{array}$ & 2011 & $\begin{array}{l}\text { Conscientização } \\
\text { das mulheres } \\
\text { sobre o vírus do } \\
\text { papiloma } \\
\text { humano e } \\
\text { problemas de } \\
\text { saúde } \\
\text { relacionados. }\end{array}$ \\
\hline $\begin{array}{l}\text { An Assessment of Gynecological Cytology } \\
\text { Screening Practices Among Health Care Providers } \\
\text { Nationwide }\end{array}$ & 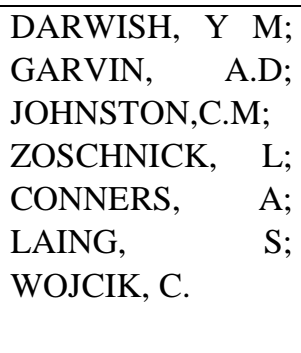 & 2015 & $\begin{array}{l}\text { Coletar } \\
\text { informações de } \\
\text { profissionais } \\
\text { certificadas em } \\
\text { Papanicolau e } \\
\text { testes de } \\
\text { papiloma vírus } \\
\text { humano }\end{array}$ \\
\hline $\begin{array}{l}\text { NILM Pap slides from women } 30 \text { years of age and } \\
\text { older with positive high-risk HPV DNA. Focused } \\
\text { rescreening prior to report issuance, an enhanced } \\
\text { quality control measure. }\end{array}$ & $\begin{array}{lr}\text { CORMIER, } & \mathrm{K} \\
\text { SCHAAF, } & \mathrm{M} ; \\
\text { HAMILTON, } & \mathrm{S} ; \\
\text { TICKMAN, } & \text { R.J; } \\
\text { PEREZ-REYES, N; } & \text { STURGIS, C.D. }\end{array}$ & 2014 & $\begin{array}{l}\text { Melhorar as } \\
\text { regulamentações } \\
\text { de } 1988 \text { (CLIA } \\
\text { '88) especificam } \\
\text { que pelo menos } \\
10 \% \\
\text { lâminas das } \\
\text { negativas de } \\
\text { Papanicolau } \\
\text { (Pap) devem ser } \\
\text { revisadas como } \\
\text { uma medida de } \\
\text { controle de } \\
\text { qualidade (QC). }\end{array}$ \\
\hline $\begin{array}{l}\text { External Quality Control of Cervical Cytopathology: } \\
\text { Interlaboratory Variability }\end{array}$ & $\begin{array}{l}\text { ÁZARA, C.Z.S; } \\
\text { MANRIQUE, } \\
\text { E.J.C; SOUZA, } \\
\text { N.L.A; } \\
\text { RODRIGUES, A.R; } \\
\text { TAVARES, S.B.N; } \\
\text { AMARAL, R.G. }\end{array}$ & 2013 & $\begin{array}{ll}\text { Comparar } & \text { a } \\
\text { variabilidade } \\
\text { dos testes de } \\
\text { triagem } \\
\text { realizados em } \\
\text { laboratórios } \\
\text { com a Unidade } \\
\text { de Controle } \\
\text { Externo da } \\
\text { Qualidade } \\
\text { (UEQC). }\end{array}$ \\
\hline
\end{tabular}




\begin{tabular}{|l|l|l|l|l|}
\hline $\begin{array}{l}\text { Quality control in cervicovaginal cytology by } \\
\text { cytohistological correlation. }\end{array}$ & $\begin{array}{l}\text { IZADI-MOOD, N } \\
\text { SARMADI, S; } \\
\text { SANII, S. }\end{array}$ & 2013 & $\begin{array}{l}\text { Determinar e } \\
\text { categorizar as } \\
\text { causas das } \\
\text { discrepâncias } \\
\text { existentes em } \\
\text { nossorário para } \\
\text { laboratório } \\
\text { esclarecer a a } \\
\text { origem dos } \\
\text { erros. }\end{array}$ \\
\hline
\end{tabular}

\section{DISCUSSÃO}

A partir das evidências científicas foi possível aglutinar as publicações em três temáticas específicas, a saber: conhecimento sobre o exame de colpocitologia oncótica; acesso ao serviço de saúde na atenção primária; e análise laboratorial.

\section{Conhecimento sobre o exame de colpocitologia oncótica}

Estudos $^{6,7}$ mostraram que o nível de conhecimento das mulheres sobre o exame é baixo em relação à doença, porém boa ao que tange à realização do preventivo sabendo reconhecer a importância deste para detecção precoce do câncer de colo de útero. Além disso, um estudo demonstrou que a procura pelo exame ocorre, na maioria das vezes, em virtude de algum sinal e/ou sintoma e não propriamente pela prevenção da doença. Assim, a falta de conhecimento traz como consequência a baixa conscientização sobre o significado, a importância do exame de Papanicolau e o restrito acesso à assistência de saúde. ${ }^{8,9}$
Outro fator que está diretamente relacionado ao conhecimento sobre $\mathrm{O}$ exame é a escolaridade, pois mulheres com nível de escolaridade menor, geralmente têm pouco acesso às informações sobre os cuidados com a saúde, fato este, que pode refletir diretamente na demanda dos exames de colpocitologia oncótica e na incidência da doença na população de baixa renda. Um estudo realizado no Brasil apontou que mulheres com escolaridade mais baixa, apresentam risco maior de desenvolver câncer de colo uterino, estando em consonância ao risco de diagnóstico tardio desse tumor. ${ }^{10}$

Portanto, faz-se necessário destacar a importância da informação sobre a necessidade e a realização do exame com a periodicidade recomendada, a fim de reduzir a morbi-mortalidade por essa patologia nas mulheres, com interação entre as informações fornecidas, as políticas preventivas, as ações dos serviços, as concepções dessas mulheres, juntamente com suas práticas ${ }^{11,12,13}$. Em países onde o rastreamento é bem 
sucedido, há diminuição das taxas de incidência e mortalidade por câncer do colo do útero, mostrando cada vez mais a importância da periodicidade do exame para as mulheres. ${ }^{14}$

\section{Acesso ao serviço de Saúde na Atenção}

\section{Primária}

O acesso aos serviços de saúde tem sido cada vez mais objeto de estudos ${ }^{15,16}$, uma vez que em virtude da crise econômica que se instalou na última década, tornou-se mais recorrente a existência de barreiras físicas e estruturais que dificultam o acesso e a procura da população pelos serviços de saúde, sobretudo na rede básica. Nesse sentido, uma análise multidimensional faz-se necessária para melhor compressão dos caracteres sociais e políticos atuais, a fim de buscar resolutividade referente à acessibilidade, organização do serviço, acolhimento, necessidades e aceitação da população quanto ao serviço. ${ }^{17,18}$

Assim, recente estudo mostrou que apenas metade das Unidades Básicas de Saúde apresentaram estrutura adequada para rastreamento do câncer de colo de útero no Brasil $^{19}$, comprometendo com isso, a integralização do cuidado e, principalmente o acesso e a qualidade da atenção. $^{20,21,22}$ No entanto, outro desafio para a efetivação de acesso equitativo aos serviços de saúde, é a grande diversidade de grupos sociais que apresentam diferentes demandas produzidas por processos sociais de exclusão, fazendo com que nem sempre essas diferenças sejam percebidas pelo poder público. ${ }^{17,23}$

Não obstante, alguns estudos $24,25,26$ apontaram que, muitas vezes o mais importante para o acesso ao serviço, ou seja, o retorno da população para a unidade de saúde, é como o profissional acolhe esse cliente no seu dia a dia, pois o acolhimento foi percebido como aspecto essencial para o estabelecimento de vínculo entre a equipe e a população. Logo, destaca-se o papel dos usuários, trabalhadores de saúde e gestores como os protagonistas na efetivação do acesso aos serviços de saúde, ou seja, para uma efetiva garantia do acesso aos serviços, todos são responsáveis com alguma forma de contribuição ao serviço. $^{20,23}$

\section{Análise Laboratorial}

Quanto à análise laboratorial, a maioria dos estudos ${ }^{27,28,29}$ diz respeito aos indicadores de qualidade interno e externo dos laboratórios conveniados ao Sistema Único de Saúde (SUS). Nesse sentido, estudo $^{29}$, realizado no Paraná com 22 laboratórios credenciados ao SUS, que realizaram exame citopatológico no período de janeiro de 2008 a dezembro de 2012, concluiu que os laboratórios apresentaram parâmetros de qualidade 
abaixo dos recomendados pelo Ministério da Saúde, fazendo-se necessário a implementação de medidas que contribuam na habilitação e qualificação dos profissionais que realizam os exames, na adequação do local de trabalho, produção, carga horária dos trabalhadores e nos indicadores de qualidade interno e externo desses laboratórios, com vistas a impactar na mortalidade de mulheres com câncer de colo de útero, a partir da redução na dualidade de resultados ou mesmo de exames falso-negativos.

Para melhorar a qualidade do exame citopatológico é necessário implementar medidas na rotina dos laboratórios, tais como programas de controle interno e externo da qualidade, que garantam a excelência dos exames em todos os setores. ${ }^{30,31,32,33}$ Outro estudo ${ }^{34}$ realizado em Goiânia, com 44 laboratórios prestadores de serviços ao SUS, mostrou que a maioria dos laboratórios apresentaram os indicadores de monitoramento interno e externo da qualidade dentro dos parâmetros recomendados pelo Ministério da Saúde, ou seja, a padronização de alguns critérios é importante para acompanhar e avaliar os procedimentos dos exames citopatológicos do colo do útero, permitindo assim, determinar áreas em que seja possível planejar e implementar ações corretivas e melhorias e, ainda, avaliar o impacto dessas ações e a incorporação de novas práticas. $^{30,35,36,37}$

Em 2012 e 2013 foram disponibilizadas duas importantes publicações para ajudar os laboratórios no monitoramento da qualidade interna e externa dos seus serviços, são elas: a primeira edição do Manual de Gestão da Qualidade para Laboratórios de Citopatologia (Instituto Nacional de Câncer José Alencar Gomes da Silva, 2012), em meio eletrônico, e a revisão do Caderno de Atenção Básica no 13: controle dos cânceres do colo de útero e de mama (BRASIL, 2013). O primeiro, com intuito de subsidiar laboratórios e gestores no processamento do exame citopatológico e o segundo, direcionado aos profissionais e gestores da Atenção Primária, para orientar quanto à qualidade da coleta do exame. ${ }^{30}$

\section{CONCLUSÃO}

A partir destes achados identificou-se a necessidade das boas práticas de enfermagem para obtenção de qualidade do material coletado para o exame citológico, a fim de evitar a grande quantidade de exames falso-negativos que são decorrentes de comportamentos inadequados dos profissionais que trabalham diretamente com esse serviço.

É importante salientar o quanto uma postura mais compreensiva dos profissionais de saúde é fundamental para 
a criação de um vínculo de confiança com a população feminina que procura as unidades básicas de saúde para a realização do exame citopatológico, para que possam entender a finalidade do exame, bem como sua importância na prevenção do câncer de colo de útero, possibilitando-lhes uma melhor qualidade de vida, além de contribuir na periodicidade do mesmo, de forma mais consciente e eficaz.

Por fim, sob o ponto de vista da pesquisa, faz-se necessário cada vez mais criar programas que visem contribuir com o monitoramento da qualidade dos laboratórios prestadores de serviço ao SUS e à população em geral, para que seja possível, em pesquisas futuras, analisar-se o quanto as condutas profissionais podem influenciar na saúde da população de forma negativa ou positiva.

As limitações deste estudo dizem respeito à indisponibilidade de algumas publicações para acesso ao texto completo, assim como por ter sido realizado em um recorte temporal de 11 anos.

\section{REFERÊNCIAS}

1. Instituto Nacional do Câncer José Alencar Gomes da Silva. Estimativa 2016: incidência de câncer no Brasil [Internet]. Rio de Janeiro: INCA; 2015 [citado em 13 jul 2017]. Disponível em: http://www.inca.gov.br/bvscontrolecancer/ publicacoes/edicao/Estimativa_2016.pdf 2. Santos FAPS, Brito RS, Santos DLA. Exame papanicolau: avaliação da qualidade do esfregaço cervical. Rev Rene,
Fortaleza [Internet]. 2011 [citado em 13 jul 2018]; 12(3):645-8. Disponível em: http://www.periodicos.ufc.br/rene/article/vi ew/4308/3313

3. Conselho Federal de Enfermagem (Brasil). Resolução do COFEN N ${ }^{\circ}$ 381/2011. Normatiza a execução, pelo Enfermeiro, da coleta de material para colpocitologia oncótica pelo método de Papanicolau [Internet]. Brasília, DF: COFEN; 2011[citado em 13 jul 2018]. Disponível em:

http://www.cofen.gov.br/resoluo-cofen-n3812011_7447.html

4. Pena MM, Silva EMS, Tronchin DMR, Melleiro MM. The use of the quality model of Parasuraman, Zeithaml and Berry in health services. Rev Esc Enferm USP. [Internet]. 2013 [citado em 13 jul 2018]; 47(5):1227-32. Disponível em: http://www.scielo.br/pdf/reeusp/v47n5/008 0-6234-reeusp-47-05-1227.pdf

5.Ganong LH. Integrative reviews of nursing research. Res Nurs Health. 1987; 10(1):1-11.

6. Nascimento LC, Nery IS, Silva AO. Conhecimento cotidiano de mulheres sobre a prevenção do câncer de colo do útero. Rev Enferm UERJ [Internet]. 2012 [citado em 13 jul 2018]; 20(4):476-80. Disponível em: http://www.e-

publicacoes.uerj.br/index.php/enfermagem uerj/article/view/4813/3537

7. Santos AMR, Holanda JBL, Silva JMO, Santos AAP, Silva EM. Câncer de colo uterino: conhecimento e comportamento de mulheres para prevenção. Rev Bras Promoç Saúde [Internet]. 2015 [citado em 13 jul 2018]; 28(2):153-159. Disponível em:

http://periodicos.unifor.br/RBPS/article/vie w/3066

8. Souza K, Paixão GP, Almeida E, Sousa A, Lirio J, Campos L. Educação popular como instrumento participativo para a prevenção do câncer ginecológico: percepção de mulheres. Rev Cuid. [Internet]. 2015 [citado em 13 jul 2018]; 6(1):892-9. Disponível em: 
http://dx.doi.org/10.15649/cuidarte.v6i1.12 9

9.Feliciano C, Christen K, Velho MB.

Câncer de colo uterino: realização do exame colpocitológico e mecanismos que ampliam sua adesão. Rev Enferm UERJ. [Internet]. 2010 [citado em 13 jul 2018]; 18(1):75-9. Disponível em: http://www.facenf.uerj.br/v18n1/v18n1a13 .pdf

10.Mascarello KC, Zandonade E, Amorim MHC. Análise da sobrevida de mulheres com câncer do colo do útero atendidas em hospital de referência para oncologia no Espírito Santo, Brasil, nos anos de 2000 a 2005. Cad Saúde Pública [Internet]. 2013 [citado em 13 jul 2018]; 29(4):823-31. Disponível em: http://www.scielo.br/pdf/csp/v29n4/19.pdf 11.Souza AF, Costa LHR. Conhecimento de mulheres sobre HPV e câncer do colo do útero após consulta de enfermagem.

Rev Bras Cancerol. [Internet]. 2015 [citado em 13 jul 2018]; 61(4):343-350.

Disponível em:

http://www.inca.gov.br/rbc/n_61/v04/pdf/0 5-artigo-conhecimento-de-mulheres-sobrehpv-e-cancer-do-colo-do-utero-aposconsulta-de-enfermagem.pdf

12. Rodrigues BC, Carneiro ACMO, Silva TL, Solá ACN, Manzi NM, Schechtman NP, et al. Educação em saúde para a prevenção do câncer cérvico-uterino. Rev Bras Educ Méd. [Internet]. 2010 [citado em 13 jul 2018]; 36 (1Supl1):149-54. Disponível em:

http://www.scielo.br/pdf/rbem/v36n1s1/v3 6n1s1a20.pdf

13. Silva MM, Gitsos J, Santos NLP. Atenção básica em saúde: prevenção do câncer de colo do útero na consulta de enfermagem. Rev Enferm UERJ.

[Internet]. 2013 [citado em 13 jul 2018]; 21(Esp1):631-6. Disponível em: $\underline{\mathrm{f}}$ http://www.epublicacoes.uerj.br/index.php/enfermagem uerj/article/view/10039/7825 14.Laganá MTC, Silva MMP, Lima LF, França TLB. Alterações citopatológicas, doenças sexualmente transmissíveis e periodicidade dos exames de rastreamento em Unidade Básica de Saúde. Rev Bras Cancerol. [Internet]. 2013 [citado em 13 jul 2018]; 59(4):523-530. Disponível em: http://www1.inca.gov.br/rbc/n_59/v04/pdf/ 05-artigo-alteracoes-citopatologicasdoencas-sexualmente-transmissiveisperiodicidade-exames-rastreamentounidade-basica-saude.pdf

15.Kopach R, De Laurentis P-C, Lawley M, Muthuraman K, Ozsen L, Rardin R, et al. Effects of clinical characteristics on successful open access scheduling. Health Care Manag Sci. [Internet]. 2007 [citado em 13 jul 2018]; 10(2):111-124.

Disponível em:

https://link.springer.com/content/pdf/10.10 07\%2Fs10729-007-9008-9.pdf

16. Carvalho VF, Kerber NPC, Wachholzv A, Pohlmann FC, Marques LA, Francioni FF. Access to papanicolaou test by the Unified Health System users. Rev Rene. [Internet]. 2016 [citado em 13 jul 2018]; 17(2):198-207. Disponível em: http://periodicos.ufc.br/rene/article/view/2 998/2313

17.Thiede M, McIntyre D. Information, communication and equitable access to health care: a conceptual note. Cad Saúde Pública [Internet]. 2008 [citado em 13 jul 2018]; 24(5):1168-1173. Disponível em: http://www.scielo.br/pdf/csp/v24n5/25.pdf 18. Corrêa DAD, Villela WV. O controle do câncer do colo do útero: desafios para implementação de ações programáticas no Amazonas, Brasil. Rev Bras Saúde Matern Infant. [Internet]. 2008 [citado em 13 jul 2018]; 8(4):491-497. Disponível em: http://www.scielo.br/pdf/rbsmi/v8n4/15.pd $\mathrm{f}$

19.Tomasi E, Oliveira TF, Fernandes PAA, Thumé E, Silveira DS, Siqueira FV, et al. Estrutura e processo de trabalho na prevenção do câncer de colo de útero na Atenção Básica à Saúde no Brasil: Programa de Melhoria do Acesso e da Qualidade - PMAQ. Rev Bras Saúde Matern Infant. [Internet]. 2015 [citado em 13 jul 2018]; 15(2):171-180. Disponível em: 
http://www.scielo.br/pdf/rbsmi/v15n2/151 9-3829-rbsmi-15-02-0171.pdf

20.Brito-Silva K, Bezerra AFB, Chaves LDP, Tanaka OY. Integralidade no cuidado ao câncer do colo do útero: avaliação do acesso. Rev Saúde Publica [Internet]. 2014 [citado em 13 jul 2018]; 48:240-8. Disponível em: http://www.scielo.br/pdf/rsp/v48n2/00348910-rsp-48-2-0240.pdf

21.Mendonça FAC, Sampaio LRL; Jorge RJB; Silva RM, Linard AG, Vieira NFC. Prevenção do câncer de colo uterino: adesão de enfermeiros e usuárias da atenção primária. Rev Rene. [Internet]. 2011 [citado em 13 jul 2018]; 12(2):26170. Disponível em:

http://periodicos.ufc.br/rene/article/view/4 $196 / 3248$

22. Bottari CMS, Vasconcellos MM, Mendonça MHM. Câncer cérvico-uterino como condição marcadora: uma proposta de avaliação da atenção básica. Cad Saúde Pública [Internet]. 2008 [citado em 13 jul 2018]; 24(Supl1):111-122. Disponível em: http://www.scielo.br/pdf/csp/v24s1/16.pdf 23. Assis MMA, Jesus WLA. Acesso aos serviços de saúde: abordagens, conceitos, políticas e modelo de análise. Ciênc Saúde Colet. [Internet]. 2012 [citado em 13 jul 2018]; 17(11):2865-2875. Disponível em: http://www.scielo.br/pdf/csc/v17n11/v17n $11 \mathrm{a} 02 . p d f$

24. Machado LM, Colomé JS, Silva RM et al. Significados do fazer profissional na estratégia de saúde da família: atenção básica enquanto cenário de atuação. Rev Pesqui Cuid Fundam. [Internet]. 2016 [citado em 13 jul 2018]; 8(1):4026-4035. Disponível em:

http://www.seer.unirio.br/index.php/cuidad ofundamental/article/view/3384/pdf_1830 25.Jorge RJB, Sampaio LRL, Diógenes MAR, Mendonça FAC, Sampaio LL. Fatores associados a não realização periódica do exame papanicolau. Rev Rene. [Internet]. 2011[citado em 13 jul 2018]; 12(3):606-12. Disponível em: http://repositorio.ufc.br/bitstream/riufc/125 04/1/2011_art_rjbjorge.pdf
26.Viana MRP, Moura MEB, Nunes BMVT, Monteiro CFS, Lago EC.

Formação do enfermeiro para a prevenção do câncer de colo uterino. Rev Enferm. UERJ. [Internet]. 2013 [citado em 13 jul 2018]; 21(1):624-30. Disponível em: http://www.facenf.uerj.br/v21nesp1/v21e1 a11.pdf

27. Tobias AHG, Amaral RG, Diniz EM, Carneiro CM. Indicadores de qualidade dos exames citopatológicos da rede pública em Minas Gerais, Brasil. Rev Bras Ginecol Obstet. [Internet]. 2016 [citado em 13 jul 2018]; 38(2):65-70. Disponível em: http://www.scielo.br/pdf/rbgo/v38n2/01007203-rbgo-38-02-00065.pdf

28.Ázara CZS, Manrique EJC, Tavares SBN, Souza NLA, Amaral RG. Internal quality control indicators of cervical cytopathology exams performed in laboratories monitored by the External Quality Control Laboratory. Rev Bras Ginecol Obstet. [Internet]. 2014 [citado em 13 jul 2018]; 36(9):398-403. Disponível em:

http://www.scielo.br/pdf/rbgo/v36n9/01007203-rbgo-36-09-00398.pdf

29. Plewka J, Turkiewicz M, Duarte BF, Chaves MAF, Cestari C, Tartari DC.

Avaliação dos indicadores de qualidade de laboratórios de citopatologia cervical. Rev Inst Adolfo Lutz [Internet]. 2014 [citado em 13 jul 2018]; 73(2):140-7. Disponível em:

ses.sp.bvs.br/lildbi/docsonline/get.php?id= 5880

30. Ministério da Saúde (Brasil). Manual de gestão da qualidade para laboratório de citopatologia. Rio de Janeiro: Ministério da Saúde; 2016.

31.Araujo Jr, MLC, Santana DA, Almeida, LB, Quintana SBS; Silva GRF, Fonseca

CSPR. Quality in cytopathology: an analysis of the internal quality monitoring indicators of the Instituto Nacional de Câncer. J Bras Patol Med Lab. [Internet]. 2015 [citado em 13 jul 2018]; 51(2):102107. Disponível em: http://www.scielo.br/pdf/jbpml/v51n2/167 6-2444-jbpml-51-02-0102.pdf 
32. Darwish YM, Garvin AD; Johnston CM, Zoschnick L, Conners A, Laing S, Wojcik C. An assessment of gynecological cytology screening practices among health care providers nationwide. Arch Pathol Lab Med. [Internet]. 2015 [citado em 13 jul 2018]; 139(5):650-655. Disponível em: http://www.archivesofpathology.org/doi/pd f/10.5858/arpa.2013-0620-OA 33.Ázara CZS, Manrique EJC, Souza NLA, Rodrigues AR, Tavares SBN, Amaral RG. External quality control of cervical cytopathology: interlaboratory variability. Acta Cytol. [Internet]. 2013 [citado em 13 jul 2018]; 57:585-590. Disponível em: https://www.karger.com/Article/Pdf/35384 3 34.Ázara CZS, Araújo ES, Magalhães JC; Amaral RG. Avaliação dos indicadores da qualidade dos exames citopatológicos do colo do útero de laboratórios privados do Estado de Goiás credenciados pelo Sistema Único de Saúde. Rev Bras Cancerol. [Internet]. 2014 [citado em 13 jul 2018]; 60(4):295-303. Disponível em: http://www1.inca.gov.br/rbc/n_60/v04/pdf/ 03-artigo-avaliacao-dos-indicadores-daqualidade-dos-exames-citopatologicos-docolo-do-utero-de-laboratorios-privados-doestado-de-goias-credenciados-pelosistema-unico-de-saude.pdf
35. Akyuz A,Yilmaz C, Yenen MC,Yavan T, Kiliç A.Women's awareness of the human papilloma virus and related health problems. J Adv Nurs. [Internet]. 2011 [citado em 13 jul 2018]; 67(12):2703-12. Disponível em: https://onlinelibrary.wiley.com/doi/abs/10. 1111/j.1365-2648.2011.05693.x 36.Cormier K, Schaaf M, Hamilton S, Tickman RJ, Perez-Reyes N, Sturgis CD. NILM Pap slides from women 30 years of age and older with positive high-risk HPV DNA. Focused rescreening prior to report issuance, an enhanced quality control measure. Am J Clin Pathol. [Internet]. 2014 [citado em 13 jul 2018]; 141:494500. Disponível em: https://academic.oup.com/ajcp/article/141/ 4/494/1760809

37. Izadi-Mood N, Sarmadi S, Sanii S. Quality control in cervicovaginal cytology by cytohistological correlation.

Cytopathology [Internet]. 2013 [citado em 13 jul 2018]; 24(1):33-38. Disponível em: https://onlinelibrary.wiley.com/doi/pdf/10. 1111/j.1365-2303.2011.00926.x

RECEBIDO: 23/11/2017

APROVADO: $26 / 04 / 2018$

PUBLICADO: $07 / 2018$ 